\title{
Lucilia sericata strain from Colombia: Experimental Colonization, Life Tables and Evaluation of Two Artificial Diets of the Blowfly Lucilia sericata (Meigen) (Diptera: Calliphoridae), Bogotá, Colombia Strain
}

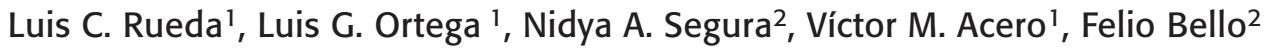 \\ 1 Universidad de La Salle, Facultad de Veterinaria, Carrera 2 No. 10-70, Bogotá, Colombia ${ }^{2}$ Universidad del Rosario, Facultad de Ciencias \\ Naturales y Matemáticas, Calle 63D No. 24-31, Bogotá, Colombia, e-mail. felio.bello@urosario.edu.co
}

\begin{abstract}
The objective of this work was to establish, under experimental laboratory conditions, a colony of Lucilia sericata, Bogotá-Colombia strain, to build life tables and evaluate two artificial diets. This blowfly is frequently used in postmortem interval studies and in injury treatment. The parental adult insects collected in Bogotá were maintained in cages at $22^{\circ} \mathrm{C} \pm 1$ average temperature, $60 \% \pm 5$ relative humidity and $12 \mathrm{~h}$ photoperiodicity. The blowflies were fed on two artificial diets that were evaluated over seven continuous generations. Reproductive and population parameters were assessed. The life cycle of the species was expressed in the number of days of the different stages: egg $=0.8 \pm 0.1$, larvae $\mathrm{I}=1.1 \pm 0.02$, larvae $\mathrm{II}=1.94 \pm 0.16$, larvae $\mathrm{III}=3.5 \pm 0.54$, pupae $=6.55 \pm 0.47$, male adult $=28.7 \pm 0.83$ and female adult $=33.5 \pm 1.0$. Total survival from egg stage to adult stage was $91.2 \%$ for diet 1 , while for diet 2 this parameter was $40.5 \%$. The lifetime reproductive output was $184.51 \pm 11.2$ eggs per female. The population parameters, as well as the reproductive output of the blowflies that were assessed, showed relatively high values, giving evidence of the continuous increase of the strain over the different generations and making possible its maintenance as a stable colony that has lasted for more than two years.
\end{abstract}

Key terms: Lucilia sericata - diet - fecundity - life cycle - life table.

\section{INTRODUCTION}

Lucilia sericata (Meigen, 1826) (Diptera: Calliphoridae) is a necrophagous fly that is important in forensic medicine because it is used as a biological indicator in estimating post-mortem interval (PMI) (Anderson, 2000; Tarone \& Foran, 2008; Zurawski et al., 2009). It also has a significant role in human medicine because its larvae are used for healing chronic injuries that do not respond to conventional treatments, such as ulcers containing gangrenous or necrotic tissue (Church \& Courtenay, 2002; Cartier \& Combemale, 2008; Gupta, 2008). Additionally, in many parts of northern Europe this blowfly is characterized as a facultative ectoparasite responsible for primary cutaneous myiasis in sheep (Hall \& Wall, 1995), with major economic impact (French et al., 1992).

The species has been described as having a holarctic distribution and is also found in Australia (Smith 1986), but it could be found anywhere in the world. In the neotropical zone there are reports of its distribution in Colombia, Argentina, Brazil, Chile and Peru (Pape et al., 2004; Figueroa et al.,
2007). In Colombia, its presence has been recorded in the Departments of Antioquia, Cundinamarca, Santander and Sucre (Pape et al., 2004). L. sericata is considered as a sinantropic species, i.e. it is in close relation with human settlements.

Studies of the biological cycle of $L$. sericata have been conducted previously on samples taken from decaying corpses to determine the PMI (Kamal, 1958; Greenberg, 1991; Anderson, 2000; Grassberger \& Reiter, 2001), and some works with this species have dealt with age structure, mortality rates and reproductive output in populations in northeast Europe using samples developed under field conditions (Wall, 1993; Smith \& Wall, 1998; Hayes et al., 1999; Pitts \& Wall, 2004). However, there has been less research on life tables and reproductive and population parameters carried out under laboratory conditions with samples of the species from a neotropical country like Colombia, in order to analyze average data from several consecutive generations, as was done in the present study.

The life tables of a population are very important because they give the most 
comprehensive description of the growth, survival and fecundity of the blowflies (Abou-Zeid et al., 2003). A vertical life table is used to analyze survival or mortality in different stages of life (Southwood, 1978), while a horizontal life table is used to estimate reproductive and population parameters. Given the importance of $L$. sericata in human and veterinary medicine, deeper knowledge is needed of its life cycle, life tables and reproductive and population parameters, since this information can support the mass rearing of larvae under laboratory conditions to be used in larval therapy and can also contribute to control strategies of the blowfly population in nature.

The food consumed by $L$. sericata under laboratory conditions is a key factor because it affects biological developmental and population dynamics. Natural diets such as beef liver that are often used in laboratory rearing of flies produce offensive odors and contamination (Sherman \& My-Tien Tran, 1995). As well, it has recently been demonstrated that the presence of toxins in decomposing tissues from natural diets can alter the development rate and generate errors in PMI estimates when necrophagous insects are used for forensic studies in the laboratory (Estrada et al., 2009). Several artificial diets have been proposed and developed as alternatives for the maintenance and rearing of L. sericata (Tachibana \& Numata, 2001). However, some of these diets may not meet the optimal nutritional requirements for nourishing specific strains of the species. Therefore, it is necessary to evaluate new diets and use life tables to analyze and understand the impact on growth, survival, reproduction, and population parameters.

The main purpose of this work was to establish under laboratory conditions a colony of L. sericata, from samples of adult specimens collected in Bogotá, Colombia, to build life tables and to evaluate two artificial diets.

\section{MATERIALS AND METHODS}

Sampling information - Adult L. sericata were collected at the San Martín meat processing plant in Bogotá, Colombia. Three-pound portions of pig liver were used as bait to attract the blowflies, which were carefully captured by using entomological nets and immediately stored in glass jars, and then transported in a polystyrene icebox to the laboratory of Medical and Forensic Entomology of the Universidad del Rosario. Insect collections were carried out for two weeks, conducted in the mornings for two the highest population densities of flies were observed in the early hours of the morning when the sunlight is less intense than the rest of the day. Collections of adult flies continued until a sufficient number of specimens for the colonization process had been captured.

Maintenance of blowflies in the laboratory - The work was conducted between February 2006 and April 2007. The taxonomic identification of the material captured in field was carried out by using the taxonomic keys of Carvalho \& Ribeiro, (2000) and Mariluis \& Peris, (1984). These keys were only applied to the identification of adult specimens. Adult forms of L. sericata were kept in $45 \times 45 \times 45 \mathrm{~cm}$ Gerberg cages at $22^{\circ} \mathrm{C} \pm 1$ average temperature, 60 $\% \pm 5$ relative humidity and $12 \mathrm{~h}$ photoperiodicity, protected with an external tulle veil to avoid the entry of other insect species. There was a flask with a cotton pad soaked in a sugar solution in each cage to provide a carbohydrate source. On a daily basis cages, containers and other utensils proper to the colony were cleaned. Every 45 days the cages were washed with water and detergent and then sterilized in an autoclave.

Diets and life cycle - Two artificial diets were evaluated. Diet 1, designed and standardized at our laboratory, consisted of a mix of nutritious agar (4.6 g), ram blood (25 $\mathrm{ml})$, powdered liver $(6 \mathrm{~g})$, BHI broth $(4.2 \mathrm{~g})$, sodium acid phosphate $(0.012 \mathrm{~g})$, potassium acid phosphate (0.012 $\mathrm{g})$, sodium chloride $(1.2 \mathrm{~g})$, glucose $(1.2 \mathrm{~g})$ and distilled water $(100 \mathrm{ml})$. Diet 2, proposed by Gingrich et al. (1971), modified by Brown \& Snow, (1979) and adapted by our group, consisted of blood flour ( $9 \mathrm{~g})$, egg flour (6 g), powdered milk (6 g), agar $(2.5 \mathrm{~g})$ and water $(100 \mathrm{ml})$. Both diets were prepared with prior sterilization of the solutions in a type II biological safety cabinet to avoid any type of contamination.

Eggs of L. sericata were gathered daily from the nutritious substrate of each diet, counted, and then placed in glass jars with a new sterile nutritious substrate of the same diet, and covered with sterilized veils. The larvae that favorably hatched from the eggs and passed from one instar to another were counted and all were maintained under the same environmental conditions as the adult organisms. When the larvae reached the third instar they were transferred to wide-mouthed jars filled with sterilized sand where pupation occurred and the corresponding counting was carried out. Finally, when the adult flies emerged, males and females were registered and put together in cages for continuing the life cycle.

Vertical life table and estimation of mortality The vertical life table was developed from two independent cohorts of 30 female and 30 male virgin adults born on the same day. After a crossing period, the 30 parental females suitable for oviposition from the second to the seventh generation were used, both for diet 1 and diet 2, and placed in separate cages. The eggs on the substrate of each diet were 
collected and the daily counting of the different life cycle stages was performed in order to evaluate the effects of the two diets. Based on the vertical life table, mortality rates (Rabinovich, 1980) and survival curves were established.

Horizontal life table and estimation of reproductive and population parameters - The horizontal life table was developed based on one cohort of 30 adult female flies born the same day and taken from the seventh generation; these were left for a period of five days with the males since this is the estimated time to start oviposition after having hatched from the pupae. The females were then individually placed in jars (30 jars with the diet that showed better results) where egg laying occurred. Eggs, laid by each fly until its death, were counted daily. Finally, the necropsy was carried out on the 30 females that completed the adult stage and died, in order to establish the number of eggs retained by them. Based on the horizontal life table, reproductive and population parameters such as fecundity, reproductive value $(\mathrm{Vx})$, net rate of reproduction ( $\mathrm{Ro}$ ), mean generation time (Tc), innate ability of population increase (rc), intrinsic rate of population increase $(r)$, finite rate of population increase $(\lambda)$ and natural rate of population increase $(\mathrm{rm})$ were calculated following the procedure described by Cárdenas et al., (1999). The construction of the horizontal life table was based on the methods of Pianka, (1998); Rabinovich, (1980), and Southwood, (1978).

Statistical analysis - Descriptive statistical parameters were used for each stage of the blowfly's life cycle. A two-way ANOVA was used to compare the data obtained from the two diets. Likewise, Tukey and Scheffé tests were used to statistically determine significant differences among stages of the fly's life cycle. The results were developed with the 14.0 version of the SPSS program. The data used for ANOVA and Tukey and Scheffé tests were generated from the vertical life table.

\section{RESULTS}

Determination of life cycle of L. sericata - Life cycle duration of $L$. sericata was determined by taking this parameter based on diet 1 , which resulted in a higher efficiency over six consecutive generations (G2 to G7), and recording the average time both in days and hours, for the different stages in this species (Table I).

Analysis stage-specific mortality on both diets - Table II shows the results for both diets derived from the vertical life table, where $a x$ is the result of the daily counting of the individuals observed in different

Table I

Life cycle of Lucilia sericata under laboratory conditions

DURATION

\begin{tabular}{cccc}
$\begin{array}{c}\text { LIFE CYCLE } \\
\text { STAGES }\end{array}$ & (DAYS / HOURS) & SD & VC \\
\hline Egg & $0.8 / 19.2$ & 0.1 & 0.12 \\
Larvae I & $1.1 / 26.4$ & 0.02 & 0.01 \\
Larvae II & $1.94 / 46.56$ & 0.16 & 0.08 \\
Larvae III & $3.5 / 84$ & 0.54 & 0.15 \\
Pupae & $6.55 / 157.2$ & 0.47 & 0.07 \\
Male adult & $28.7 / 688.8$ & 0.83 & 0.02 \\
Female adult & $33.5 / 804$ & 1 & 0.02 \\
\hline
\end{tabular}

$\mathrm{SD}=$ Standard Deviation. $\mathrm{VC}=$ Variation Coefficient

Table II

Vertical life table for Lucilia sericata on the two diets

\begin{tabular}{|c|c|c|c|c|c|c|}
\hline$x$ & Diet & ax & lx & $d x$ & $q x$ & $K x$ \\
\hline \multirow[t]{2}{*}{ Egg } & 1 & 904 & 1 & 0.035 & 0.04 & 0.016 \\
\hline & 2 & 893 & 1 & 0.305 & 0.3 & 0.158 \\
\hline \multirow[t]{2}{*}{ Larvae I* } & 1 & 872 & 0.965 & 0.019 & 0.02 & 0.01 \\
\hline & 2 & 621 & 0.695 & 0.198 & 0.29 & 0.15 \\
\hline \multirow[t]{2}{*}{ Larvae II* $^{*}$} & 1 & 855 & 0.946 & 0.012 & 0.01 & 0.01 \\
\hline & 2 & 444 & 0.497 & 0.076 & 0.15 & 0.07 \\
\hline \multirow[t]{2}{*}{ Larvae III* } & 1 & 844 & 0.934 & 0.013 & 0.01 & 0.01 \\
\hline & 2 & 376 & 0.421 & 0.011 & 0.03 & 0.01 \\
\hline \multirow[t]{2}{*}{ Pupae* } & 1 & 832 & 0.92 & 0.009 & 0.01 & 0 \\
\hline & 2 & 366 & 0.41 & 0.004 & 0.01 & 0 \\
\hline \multirow[t]{2}{*}{ Adult* } & 1 & 824 & 0.912 & & & \\
\hline & 2 & 362 & 0.405 & & & \\
\hline
\end{tabular}

$x=$ life cycle stages, $a x=$ number of individuals observed in each stage, $\mid x=$ percentage of the original cohort that survives at the beginning of each stage, $\mathrm{dx}=$ percentage of the original cohort that dies in each stage, $\mathrm{qx}=$ mortality rate (average probability of death that an individual has), $k x=$ force of mortality. *Significant differences $(P<0.05)$. 
life cycle stages for the species $L$. sericata and $l x$ is a higher number of survivors of each stage for diet 1 . Thus, lower survival rates from egg to adult were observed for diet 2, showing significant differences from larva I to adult. In $d x$ it can be observed that mortality has a similar behavior to column $l x$, showing a trend that is inversely proportional for the two columns; in $q x$, the average probability of death of the individuals for diet 1 is very low, while for diet 2 this probability is high in the stages from egg to larva II; in $k x$, the force of mortality is higher in diet 2, the differences between the two diets being higher in diet 2 in the stages from egg to larva II. In general, the survival of larval stages was of $96.5 \%$ \pm 4.5 for diet 1 (3.5\% mortality), while for diet 2 it was of $69.5 \%, \pm 2.43$ (30.5\% mortality). Total survival from egg to adult stage was represented by a value of $91.2 \% \pm 3.45$ for diet $1(8.8 \%$ mortality), while for diet 2 this parameter was of $40.5 \% \pm 2.88(59.5 \%$ mortality).

Survival curves of L. sericata obtained from both diets - The survival curve of $L$. sericata for diet 1 , according to the classification of Rabinovich (1980), is a type IV curve because it represents a population in which there is a "constant fraction" of individuals dying in each age interval. The survival curve obtained with diet 2 is characterized as type III curve that corresponds to populations with very high mortality rates at the beginning of life (Fig. 1).

Horizontal life table and determination of reproductive and population parameters - The following fecundity values were obtained: the average number of oviposition was $6.44 \pm 1.6$ batches per female. The mean eggs laid per female were $184.51 \pm 11.2$, with a maximum number of $199 \pm 16.3$ and a minimum of $172.9 \pm 20.5$. Finally, the total mean of eggs per female during the whole life span of L. sericata was $1190 \pm 45.9$, with a maximum of $1592 \pm 63.8$ and a minimum of $712 \pm 56.4$. The reproductive value $(V x)$ of the females in the cohort at 27.5 days was 80.44 (Table III).

The predictive population parameters were estimated in absence of mortality according to Southwood (1978). The following values were obtained from Table III: net reproductive rate Ro $=586.84$ female offspring per cohort female; mean generation time $\mathrm{Tc}=17.81$ days; innate ability of population increase $\mathrm{rc}=0.44$ days; the natural rate of increase $\mathrm{rm}=0.6$ female offspring for each cohort female per day, and the finite rate of population increase $\lambda=1.85$ individuals per female per day.

\section{DISCUSSION}

Results of this research show highly significant differences for mortality in larval stage, survival adult percentage in the comparison of the two artificial diets, indicating that using diet 1 is more efficient in the developmental process of all the life cycle stages of $L$. sericata. One of the possible causes of this difference, which had a remarkable impact at the population level, could be the limited quality of diet 2, i.e., the substances that composed this diet did not completely meet the nutritional

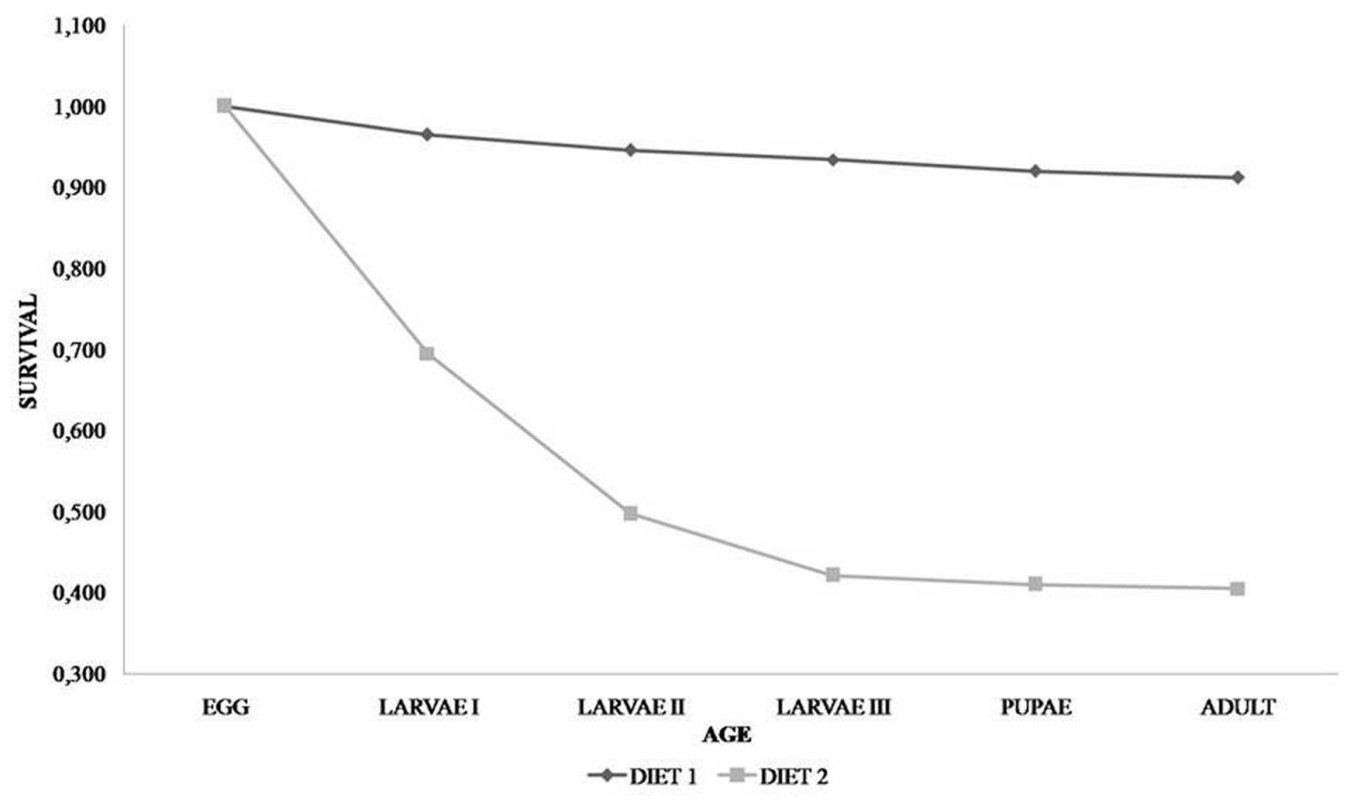

Figure 1: survival curve of Lucilia sericata obtained from the two diets. 
Table III

Horizontal life table for Lucilia sericata

\begin{tabular}{lccccc}
\hline $\mathrm{x}$ & $\mathrm{lx}$ & $\mathrm{mx}$ & $1 \mathrm{xmx}$ & $\mathrm{xlxmx}$ & $\mathrm{Vx}$ \\
\hline 0.5 & 1 & 0 & 0 & 0 & 1.36 \\
1.5 & 1 & 0 & 0 & 0 & 2.51 \\
2.5 & 1 & 0 & 0 & 0 & 4.65 \\
3.5 & 1 & 0 & 0 & 0 & 8.61 \\
4.5 & 1 & 0 & 0 & 0 & 15.94 \\
5.5 & 1 & 0 & 0 & 0 & 29.49 \\
6.5 & 1 & 25.28 & 25.28 & 164.32 & 54.58 \\
7.5 & 1 & 24.64 & 24.64 & 184.80 & 54.21 \\
8.5 & 1 & 29.36 & 29.36 & 249.56 & 54.72 \\
9.5 & 1 & 14.72 & 14.72 & 139.84 & 46.93 \\
10.5 & 1 & 30.84 & 30.84 & 323.82 & 59.60 \\
11.5 & 1 & 28.2 & 28.2 & 324.30 & 53.22 \\
12.5 & 1 & 14.20 & 14.20 & 177.50 & 46.30 \\
13.5 & 1 & 27.32 & 27.32 & 368.82 & 59.40 \\
14.5 & 1 & 29.60 & 29.60 & 429.20 & 59.35 \\
15.5 & 1 & 28.52 & 28.52 & 442.06 & 55.06 \\
16.5 & 1 & 17.08 & 17.08 & 281.82 & 49.10 \\
17.5 & 1 & 28.08 & 28.08 & 491.40 & 59.25 \\
18.5 & 1 & 25.12 & 25.12 & 464.72 & 57.69 \\
19.5 & 1 & 28.04 & 28.04 & 546.78 & 60.26 \\
20.5 & 1 & 28.92 & 28.92 & 592.86 & 59.62 \\
21.5 & 0.96 & 29.79 & 28.6 & 614.86 & 59.17 \\
22.5 & 0.92 & 27.74 & 25.52 & 574.21 & 56.73 \\
23.5 & 0.84 & 25.38 & 21.32 & 501.00 & 58.76 \\
24.5 & 0.84 & 38.24 & 32.12 & 786.97 & 61.77 \\
25.5 & 0.6 & 34.27 & 20.56 & 524.33 & 60.95 \\
26.5 & 0.48 & 25.50 & 12.24 & 324.36 & 61.72 \\
27.5 & 0.4 & 48.80 & 19.52 & 536.80 & 80.44 \\
28.5 & 0.4 & 30.80 & 12.32 & 351.12 & 58.54 \\
29.5 & 0.32 & 26.75 & 8.56 & 252.52 & 64.16 \\
30.5 & 0.28 & 62.29 & 17.44 & 531.95 & 79.12 \\
31.5 & 0.12 & 72.67 & 8.72 & 274.69 & 72.67 \\
32.5 & 0 & 0 & 0 & 0 & 0 \\
\hline & & & $R o=586,84$ & 10454,64 \\
& & & & &
\end{tabular}

$\mathrm{x}=$ class of female age in the cohort, expressed in days; $\mathrm{lx}=$ the survival proportion of the cohort females at age $(x) ; m x=$ average of the female fecundity (corrected for sex ratio) by each cohort female of age $(x) ; v x=$ reproductive value of the females in the cohort at $x$ age; $R_{0}=$ net rate of reproduction.

requirements of the insects, requirements that were fulfilled by diet 1, although in Cochliomyia hominivorax species diet 1 achieved efficient results when it was evaluated in the development of the biological cycle of this insect (Alvarez et al., 2005). Females of $L$. sericata that are anautogenous require a protein meal to initiate vitellogenesis (Hayes et al., 1999). To that end, the contribution of powdered liver, BHI and blood, which are protein sources in diet 1 , were probably more optimal than the protein sources in diet 2 . This contribution helped the formation of embryos with better potential abilities for adaptation and development (BartonBrowne, 2001). The immature forms resulting from these embryos were able to successfully continue through the different stages of the fly's biological cycle until reaching the adult stage. This situation was in contrast to that of the embryos initiated with the proteins provided by diet 2 , which became less apt specimens. Likewise, when the larvae hatched, the protein substances and other nutritious sources available in diet 1 may have promoted the adaptation ability and the early development indicated, with the aforementioned result of lower mortality in the first stages of the biological cycle as compared to the mortality rates of insects fed with diet 2 .

A theory of Davies \& Hobson (1935) suggests that the most important factor, after nutrients, for survival in the first stages of the life cycle is humidity. Given the different compositions of the two diets, it was possible that premature desiccation occurred with diet 2, taking into account that the environmental conditions under which the insects were maintained, for both immature and adult individuals, were the same for the two dietary groups. It is possible that lack of mineral salts in diet 2 contributed to greater water loss through evaporation.

In general, the comparison of the vertical life tables for diets 1 and 2 indicate that the survival percentage was higher in the life table of the individuals fed on diet 1, while the mortality parameters (percentage, rate and force) had higher values in the life table for specimens from diet 2, mainly in the first stages of the biological cycle. This confirms that the efficiency of diet 1 contributed to quality and quantity of the nutrients needed for optimum development of the life cycle stages of L. sericata under laboratory conditions. As well, differences are evidenced in the survival curves, type IV corresponding to diet 1 and type III corresponding to diet 2 (Fig. 1), where a constant population of individuals dying in each time interval is clearly observed in the former and a high mortality rate in the early biological stages is observed in the latter. This confirms the previous reasoning on the effectiveness of diet 1 .

The average duration of the life cycle described in this research for L. sericata, from egg to pupae (13.89 days / 333.36 hours), is shorter in comparison to data provided by Usaquén \& Camacho (2004) (26 days under natural environmental conditions), Nuorteva, (1977) (23-28 days under field conditions), and Anderson, (2000) (32 days at $16^{\circ} \mathrm{C}$ and 20 days at $21^{\circ} \mathrm{C}$ ), and similar to the information by Kamal, (1958) (12-15 days at $22^{\circ} \mathrm{C}$ and $50 \%$ relative humidity) and Anderson, (2000) (14 days at $27^{\circ} \mathrm{C}$ ). Important differences were observed for the various biological stages because each stage presented a different period for development. According to Tachibana \& Numata, 
(2001), the artificial diet based on powdered milk can cause a lower duration of larval stages in comparison to the diets traditionally used, as often occurs with liver explanted from animals. However, this did not occur in the present work with diet 2, which included substances that resulted in longer periods of larval than of insects fed on diet 1 . In addition to the efficiency of dietary components, it is necessary to periodically provide the insects with fresh food in order to shorten larval stage development. As well, an appropriate substrate should be provided to the prepupae to accelerate growth and development (Tarone, 2006). These considerations were equally applied throughout this work with both diets. Nevertheless, there were evident differences that were more ideal for the insects fed with diet 1 .

In the analysis of reproductive and population parameters, the value of 586.84 was obtained for the net reproduction rate (Ro), showing that the population was in active growth as the result is higher than 1 (Cárdenas et al., 1999), while AbouZeid et al., (2003) showed a lower value of $R o=106.1$ for L. cuprina, which they considered high. The fecundity results we obtained were similar to those of other works on blowflies (Hayes et al., 1999, Wall et al., 2001, Abou-Zeid et al., 2003). However, in these works each strain displayed its own characteristics in reproductive output. On the other hand, the mean generation time (Tc) was 17.81 days, indicating the time from the oviposition until female offspring were mature enough to oviposit their own eggs. This implies that every 17.81 days a new generation of L. sericata is present, while Abou-Zeid et al., (2003), recorded a slightly higher value of $\mathrm{Tc}=19.8$ days for L. cuprina. The finite rate of population increase $(\lambda)$ was 1.85 days. This value indicates the maximum number of individuals added by a female to the population in a given time unit; this value was similar to that achieved by Abou-Zeid et al., (2003), who determined a value of $\lambda=1.27$ days for L. cuprina. With this same parameter, Silva et al. (2003) reported values of $\lambda=-0.513$ and -0.98 for L. eximia and C. macellaria, respectively. These values are lower than those recorded in the present work. The data suggest that the increase in the colony of $L$. sericata was constant during the generations analyzed in the laboratory. The finite rate of population increase $(\lambda)$ showed that the colony of $L$. sericata maintained its development in the laboratory with an estimated rate of one individual per female per day. The maximum intrinsic rate of natural increase $\mathrm{rm}=0.6$ indicates the female offspring per female in the cohort per day, while Abou-Zeid et al., (2003), recorded a value of $\mathrm{rm}=0.236$ for L. cuprina; these data confirm, according to Rabinovich, (1980), that the intrinsic rate of natural increase is genetically determined in a particular species. The parameters analyzed show that L. sericata has a higher replacement rate, a finite rate of population increase higher than L. cuprina, L. eximia and C. macellaria, an intrinsic rate of natural increase higher than L. cuprina, and a mean generation time lower than L. cuprina.

In conclusion, the reproductive output and the population parameters of $L$. sericata had relatively high values with diet 1 , which was reflected in the optimal biological development of the blowfly cycle through the seven consecutive generations analyzed under controlled laboratory conditions, making possible the maintenance of the population as a colonized strain that has lasted for more than two years. This knowledge could provide support to mass rearing of larvae under laboratory conditions, in order to be used for several basic and applied studies in biomedicine.

\section{ACKNOWLEDGMENT}

We thank Estrella Cárdenas for invaluable collaboration in analyzing life tables.

\section{REFERENCES}

ABOU-ZEID M, GABRE R, CHI H (2003) Life table of the Australian sheep blow fly Lucilia cuprina (Wiedemann) (Diptera: Calliphoridae). Egypt J Zool 41: 29-45.

ALVAREZ A, ORTIZ M, RODRÍGUEZ G (2005) Evaluación de cuatro tipos de leche en la dieta larvaria de Cochliomyia hominivorax (Coquerel). Rev Med Vet 10: 7-21.

ANDERSON GS (2000) Minimum and maximum development rates of some forensically important Calliphoridae (Diptera). J Forensic Sci 45: 824-832.

BARTON-BROWNE L (2001) Quantitative aspects of the regulation of ovarian development in selected anautogenous Diptera: integration of endocrinology and nutrition. Entomol Exp Appl 100: 137-149.

BROWN HE, SNOW JW (1979) Screwworms (Diptera: Calliphoridae): A new liquid media for rearing screwworm larvae. J Med Entomol 16: 29-32.

CÁRDENAS E, FERRO C, CORREDOR D, MARTÍNEZ O, MUNSTERMAN L (1999) Reproductive biology of Lutzomyia shannoni (Dyar) (Diptera: Psychodidae) under experimental conditions. J Vector Ecol 24: 158-170.

CARTIER E, COMBEMALE P (2008) Maggot therapy with Lucilia sericata for debridement of chronic wounds. Ann Dermatol Venereol 135: 685-688.

CARVALHO CJB, RIBEIRO PB (2000) Chave de identificaçao das espécies de Calliphoridae (Diptera) do sul do Brasil. Rev Bras Parasitol Vet 9: 169-173.

CHURCH JC, COURTENAY M (2002) Maggot Debridement Therapy for Chronic Wounds. Int J Low Extrem Wounds 2: 129-134.

DAVIES WM, HOBSON RP (1935) Sheep blowfly investigations. I. the relationship of humidity to blowfly attack. Ann Appl Biol 22: 279-293.

ESTRADA DA, GRELLA MD, THYSSEN PJ, LINHARES AX (2009) Chrysomya albiceps (Wiedemann) (Diptera: Calliphoridae) developmental rate on artificial diet with animal tissues for forensic purpose. Neotrop Entomol 38: 203-207. 
FIGUEROA L, FLORES J, RODRÍGUEZ S (2007) Método de cultivo de larvas de moscas Lucilia sericata para terapia larval. Parasitol Latinoam 62: 79-82.

FRENCH NP, WALL R, CRIPPS, MORGAN KL (1992) Prevalence, regional distribution and control of blowfly strike in England and Wales. Veterinary Record 131: 337342.

GINGRICH RE, GRAHAM AJ, HIGHTOWER BG (1971) Media containing liquefied nutrients for mass-rearing larvae of the screwworm. J Econ Entomol 64: 673-683.

GRASSBERGER M, REITER C (2001) Effect of temperature on Lucilia sericata (Diptera: Calliphoridae) development with special reference to the isomegalen- and isomorphendiagram. J Forensic Sci 120:32-36.

GREENBERG B (1991) Flies as forensic indicators. J Med Entomol 28: 565-577.

GUPTA A (2008) A review of the use of maggots in wound therapy. Ann Plast Surg 60: 224-227.

HALL MJR, WALL R (1995) Myasis in humans and domestic animals. Adv Parasitol 35: 258-334.

HAYES EJ, WALL R, SMITH E (1999) Mortality rate, reproductive output, and trap response bias populations of the blowfly Lucilia sericata. Ecol Entomol 24: 300-307.

KAMAL AS (1958) Comparative study of thirteen species of Sarcosaprophagous Calliphoridae and Sarcophagidae (Diptera). 1. Bionomics. Ann Entomol Soc Am 51: 261-271.

MARILUIS JC, PERIS SV (1984) Datos para una sinopsis de los Calliphoridae neotropicales Eos, t, LX 67-86.

NUORTEVA P (1977) Sarcosaprophagous insects as forensic indicators. In: Tedeschi CG, Eckert WG, Tedeschi LG (eds) A study in trauma and environmental hazards. vol. II. WB Saunders, pp 1072-1095.

PAPE T, WOLFF M, AMAT E (2004) Los califóridos, éstridos, rinofóridos y sarcofágidos (Diptera: Calliphoridae, Oestridae, Rhinophoridae, Sarcophagidae) de Colombia. Biota Colombiana 5: 201-208.

PIANKA ER (1998) Evolutionary Ecology. Harper and Row, New York, $468 \mathrm{p}$.

PITTS KM, WALL R (2004) Adult mortality and oviposition rates in field and captive populations of the blowfly Lucilia sericata. Ecol Entomol 29: 727-734.
RABINOVICH JE (1980) Introducción a La Ecología de Poblaciones Animales. Compañía Ed. Continental, México City, México, 313 p.

SHERMAN RA, MY-TIEN TRAN JM (1995) A simple, sterile food source for rearing the larvae of Lucilia sericata (Diptera: Caliphoridae). Med Vet Entomol 9: 393-398.

SILVA I, MANCERA A, GODOY C (2003) Population dynamics of Lucilia eximia (Diptera: Calliphoridae). J Appl Ent 127: 2-6.

SMITH KG (1986) A Manual of forensic entomology. Department of Entomology British Museum (Natural History) and Cornell University Press. London, 205 p.

SMITH KE, WALL R (1998) Estimates of population density and dispersal in the blowfly Lucilia sericata (Diptera: Calliphoridae). Bull Entomol Res 87: 65-73.

SOUTHWOOD TRE (1978) Ecological Methods, with Particular reference to the study of Insect Populations. Chapman and Hall, London, $524 \mathrm{p}$.

TACHIBANA SI, NUMATA H (2001) An artificial diet for blow fly larvae, Lucilia sericata (Meigen),(Diptera: Calliphoridae). Appl Entomol Zool 36: 521-523.

TARONE AM, FORAN DR (2008) Generalized additive models and Lucilia sericata growth: assessing confidence intervals and error rates in forensic entomology. J Forensic Sci 53: 942-948.

TARONE AM. (2006) Components of Developmental Plasticity in a Michigan Population of Lucilia sericata (Diptera: Calliphoridae). J Med Entomol 43: 1023-1033.

USAQUÉN W, CAMACHO G (2004) Ciclo de vida de Lucilia sericata (Diptera: Calliphoridae) como primera especie colonizadora presente en hígado humano realizado en el Instituto Nacional de Medicina Legal y ciencias Forenses. Bogotá 2000. Revista INML y CF 18: 31-36.

WALL R (1993) The reproductive output of the blowfly Lucilia sericata. J Insect Physiol 39: 743-750.

WALL R, PITTS KM, SMITH KE (2001) Pre-adult mortality in the blowfly Lucilia sericata. Med Vet Entomol 15: 328-334.

ZURAWSKI KN, BENBOW ME, MILLER JR, MERRITT RW (2009) Examination of nocturnal blow fly (Diptera: Calliphoridae) oviposition on pig carcasses in midMichigan. J Med Entomol 46: 671-679. 
